in which the history pointed toward the latter. A young man otherwise apparently healthy, gave a clear history of repeated attacks of impairment of vision in the affected eye. These attacks had occurred for some years, at first at long intervals, then more frequently. The final attack occurred on a Sunday morning while he was reading the newspaper. He said the sensation was exactly similar to that experienced on former occasions. He stopped reading and sat for a few minutes waiting for it to pass off but the trouble did not pass off; and instead, vision rapidly grew worse until light perception was lost. I saw him twenty-two hours after the occurrence of the trouble. Light perception was then entirely lost. CEdema of the retina was very marked. The margins of the disc were obscured and the retinal veins contracted irregularly. There was no movement of the column of blood. The arteries were not materially altered in appearance. The patient subsequently remained in good health until the occurrence of an attack of typhoid fever from which he died.

As bearing upon a point in reference to Dr. Ayres' case, I have in mind a case which came to me last November with extensive hæmorrhage in the region of the macula and a second hæmorrhage in the neighborhood of the optic disc, neither causing complete loss of light perception. They had occurred without any apparent predisposing cause. The patient was inclined to ascribe the occurrence to exposure to tobacco smoke, which he never could stand. He had been in a room filled with smoke until he suffered from great nausea and discomfort, but had not vomited. He went on the street and coming to a street lamp noticed something wrong with the sight. There has been almost complete recovery with no recurrence of the hæmorrhage in six months, and the man is perfectly healthy in all respects, so far as can be judged by repeated careful examinations.

Dr. S. C. Ayers, Cincinnati: $-A$ curious thing is that so many cases of embolism or thrombosis occur in the morning. Many patients wake up and find the eye blind. This was the case in the three instances which I have reported. I am certain that we have some cases of genuine embolism from the fact that the arteries remain permanently obliterated. In regard to the case reported, I am sure that it could not be embolism. What it was, unless thrombosis with temporary obstruction, I do not know.

\section{"IMPURE" PARETIC DEMENTIA AND ITS FORENSIC RELATIONS.}

Read in the Section of Neurology and Medical Jurisprudence, at the Forty-third Annual Meeting of the American Medical Association, held at Detroit, Mich., June, 1892. BY JAS. G. KIERNAN, M.D.

FELLOW OF THE CHICAGO ACADFMY OF MEDICINE, LECTURER ON FORENSIC PSYCHIATRY UNION IA W SCHOOL OF CHICAGO.

Many European and some American alienists have drawn the line between insanity attacking an intact organization and attacking one already disordered by heredity or disease. What is true of insanity is also true of paretic dementia. This certainly becomes tinctured with certain features according to the organization it attacks. The organization attacked, may already be the victim of a constitutional disease like phthisis in which case the emotional exaltation of the spes phthisica becomes exaggerated with the emotional state of true paretic dementia, permeated, however, by a suspicional phase. The claim has been made that these are not paretic dementia plus the individual defect, but new types of the paretic dementia. Fournier, for example, went so far as to claim that syphilis produced a pseudoparetic dementia. I have already shown that exceedingly valid grounds exist for refusing to admit the existence of such a type. ${ }^{1} \quad$ Bonnet has recently has recently sustained my position in a memoir crowned by the French Medico-Psychological Association.
Regis has gone even further than Fournier, for he claims that beside the type of paretic dementia which becomes developed in its own time, and which is the true paretic dementia, there are other cases which occur unexpectedly, some time before, others after the ordinary period, which may be said to range between the ages of twenty-five and sixty-five years. The first may be designated as premature paretic dementia, the second as late paretic dementia. Cases before the age of twenty-five years, are very rare, and only a few cases are recorded coming on before the age of twenty. The premature type, unlike the ordinary type, has always a powerful etiological factor, such as heredity, syphilis, traumatism, saturnism, or general or local diathesis. These causes appear to determine in these cases an early predisposition, and prematurely to place the brain in those conditions in which it is found in mature life. Premature paretic dementia has a slower progress and a longer duration; it is more frequently subject to remissions, and is susceptible of a more or less permanent cure. To the designation premature and to the positiveness of the position here taken, I have elsewhere ${ }^{4}$ shown that most decided objections exist. The symptoms which Regis has grouped under this title may appear at any age, and are due to the organism attacked. A careful examination which I made of the subject some years demonstrated ago to me, ${ }^{5}$ that this was the true explanation of the facts cited by Regis in support of his position. Whatever be the etiological factor, the organism attacked tinges the paretic dementia, and not the etiological factor. The normal organization furnishes the typical paretic dement. The organism in which a neurosis has been set up by phthisis, lues, gout, rheumatism, traumatism, leadpoisoning, insolation, heredity, ataxia or other causes, furnishes atypical cases of paretic dementia presenting many features in common.

Klippe $11^{6}$ claims that among the arthritics, as among other diathesitics, types of paretic dementia may occur; pure paretic dementia, paretic dementia with complicatory neuroses, and finally the pseudoparetic dementia found in diathesitic conditions.

These atypical cases simulate those of other psychoses at various times during their progress.

Foville $^{7}$ states for example that, during the last few years, cases of paretic dementia have been noticed in which delusional states added to muscular agitation assumed alternately the form of maniacal exaltation and melancholic depression, and it has been proposed to class these as paretic dementia a double form. The chance of error that we most often meet with, is the possibility of confounding the period of excitement of circular insanity, with the beginning of the expansive period of paretic dementia. The resemblance may be very great, both as regard bodily and mental symptoms. When intellectual disorder is added to the maniacal exaltation of circular insanity, it frequently assumes the form of the grandiose delusions so frequent in paretic dements. Even when there is no delusion properly so called, the resemblance may be very great. The mind deranged with enterprises, the opinion of self in the intellectual, artistic and poetical domain, exaggerated; the optimism generalized,

4 Amer. Lancet, Vol. VII.

Alienist and Nenrologist, 1883

i Briain, Oct., $188^{\circ}$ 
in a word accompanied by impulses to theft, to ex- or fault finding. The exalted opinion is often the cesses of all kinds, to the most compromising ac- result of a delusion of memory. The same is true of tions, might produce the appearance in the two the depressional delusions, which are sometimes so psychoses of almost identical characteristics. It is thus retained, as to affect business transactions. One well known, that certain paretic dements at the on- of my patients with decided hereditary stigmata, was set of the excitement may not present any speech or attacked by paretic dementia. His periods of exaltamotor disorder. On the other hand, in certain cases tion and depression alternated twice or thrice and of circular insanity, the close connection between disappeared, leaving a paralucid querulent pessimisthe emotions and the cerebral activity may impart tic state. He has an inward conviction, from what to the speech a degree of tremulousness, very diffi- were evidently memory delusions based on this forcult to distinguish from that of paretic dementia. mer depression, that every thing was going to go Finally, as Falret has shown, in a few cases of circu- wrong with his business. Under the influence of lar insanity, pupillary derangements, apoplectiform this state he sold out some stock which, by a "bear" and epileptiform attacks have been noticed.

A pyschic element of great value would be the inception of dementia which is common enough at the onset of paretic dementia to be considered constant. But this is often so disguised in consequence of the general state of excitement, that it is almost impossible to ascertain its existence.

Regis ${ }^{8}$ thinks he has found a criterion in the nature of the patient's feelings. He claims that the paretic dement is really kind-hearted, generous and even prodigal, desirous of being agreeable to everybody, and spreading around him the treasures of a common benevolence. The patient suffering from circular insanity, is wicked above everything, cantankerous, ironical and clever in injuring everybody. We are far from denying this is often so, but we have known paretic dements, who were caustic and mischievous, and patients suffering from circular insanity, who are generous and beneficient.

Gilles claims, ${ }^{9}$ that circular paretic dementia bears the same relation to circular insanity, that exalted and depressed periods of paretic dementia do to mania an dmelancholia; circular paretic dementia is especiaily frequent in hereditary cases. The remissions occur with great suddenness and apparent completeness. In the depressed state intellectual and organic failure with trophic disorders occur, in the expansive period, temporary amelioration is likely to appear, eschars, congestive attacks, the menstrual period and acute diseases form the transition of one phase into another. Circular paretic dementia may appear suddenly after one or two attacks of simple insanity, or in the course of true circular insanity.

The alternating type is most frequent. The duration of the psychosis is longer than the ordinary type of paretic dementia.

How difficult the diagnosis between circular paretic dementia and circular insanity is, may be judged from one of my cases. A patient who has a strong hereditary taint, is regarded by me as a paretic dement, and by so excellent alienists as. Drs. Dewey and Bannister, as a circular lunatic.

The types of parotic dementia due to lues, traumatism, insolation, phthisis, lead poisoning, heredity, etc. but particularly the hereditary types, are exceedingly likely to assume this circular character.

The rheumatic and gouty types have prolonged remissions, which may, as Spitzka, Regis and myself have observed, pass into recoveries. In my experience, the other types do not recover as Regis claims, but there is a long-lasting querulent, paralucid condition, in which the patient while retaining to a limited degree his former exalted opinion of himself conceals this under resentment evinced in lawsuits

\footnotetext{
8. Éncephale, 1881

9 Medical Standard, June, 1892.
}

movement induced by a lawsuit, had been forced down in value. This law-suit and the resultant "bear" movement, had been foreseen by him when he purchased the stock. The stock rose above par within a week after he sold it. The remission gave place to a period of depression, followed by one of emotional exaltation during which he was committed to an insane hospital. Suit was brought by his conservator to annul the sale of the stock. The jury under the instructions of the court decided that the sale should stand. This decision was in full accord with repeated decisions of the Illinois and Iowa Supreme Courts, which held that persons of unsound mind are to be held bound by an executed contract or conveyance where the transaction is fair and reasonable, and in the ordinary course of business, and where the mental condition of the party is unknown to the second part, and the parties cannot be placed in status quo ante.

In another case with hereditary taint, complicated with lues, there occurred periods of paralucid querulency, emotional depression, and exaltation. The patient previous to the demonstrable onset of the paretic dementia had contracted to have two houses built. The contractor, after making several sub-contracts, failed. The sub-contractors demanded payment of the paretic for work which the contractor had been previously paid. This was refused. The patient was sent to an insane hospital, whence he was discharged in a paralucid querulent interval. Despite my advice to the contrary, he was placed in charge of his property. In a short time he verbally agreed to pay the contractors their bills. Owing to a new period of exaltation requiring hospital treatment, these promises were not fulfilled; whereupon suit was brought. The jury decided for the plaintiffs for the same reason as in the previous case.

These impure types are hence of peculiar forensic interest, since they nullify the ordinary prognosis as to the duration of remissions in paretic dementia and of the disease itself.

A prominent clinical feature of these cases is the temperature. Rottenbiller ${ }^{10}$ has found the paretic temperature is subnormal, and that extraordinary daily variations, without apparent cause, are frequent ( in one case the temperature rose from $97 \mathrm{~F}$. in the morning to $102.6 \mathrm{~F}$. in the evening, and fell again to $88 \mathrm{~F}$. the next morning); these characteris. tics are present in the early stages of the disease and in remissions.

This in my experience has been almost exclusively the case with the premature paretic dements. In these, the asymmetrical axillary temperature to which I called attention ${ }^{11}$ about a decade and a half ago is peculiarly frequent.

10 Allge. Zeitschrift f. Psych., 1885.
11 Jour. Nerv. and Mental Disease, 1878. 
Regis has sufficiently albeit too strongly covered the point of age. The luetic, gouty, rheumatic, traumatic and hereditary types occur at any age. The luetic cases resulting after the age of 65 , are of rather long duration. In three such cases, the patient reached the age of 73 , but each resided the whole period in an insane hospital. In three hereditary cases, occurring after 65 (one male, two females), of less duration ( 6 years); three sons were also afflicted at from 17 to 23 with paretic dementia. The sons died ere their parents from intercurrent complication due to trophic changes: the spinal symptoms were especially predominant. In epileptics who became paretic dements at the climacteric period the psychosis ran its usual course, and rarely lasted three years after its onset. In ataxics however, the remissions were frequent and protracted, but querulency existed.

The Hebrew race, as Spitzka $^{12}$ several years ago pointed out, seems to be peculiarly liable to this type. Heredity and lues prepare the soil which this psychosis attacks. Pure paretic dementia is, in my experience, rare with Hebrews. ${ }^{13}$

The forensic results of this type of paretic dementia, have already been shown. This psychosis constitutes at times no little financial danger to communities from the precipitation of parics.

\section{DISCUSSION OF ELECTRICAL EXECUTION.}

Read in the Section of Neurology and Medical Jurisprudence, at th Forty third annual meeting of the American Medical Association, held in Detroit, Mlch.. June, 1892.

\section{BY A. D. ROCKWELL, M.D.,} OF NEW YORK.

While I do not believe that the best use to which a man can be put is to kill him, yet all will agree that if the law will kill, let it kill decently. It is evident that the sentiment against hanging and in favor of some method quicker and less repulsive is strengthening and that other methods will sooner or later replace the rope everywhere. Mr. Edison while in Paris during the exposition gave his opinion so positively in regard to the efficiency of electricity that the medical section of the French Academy of Sciences aided by Marcel Duprez, a prominent electrician, have had the matter under careful investigation. There is always opposition and friction attending changes for the better, and this change has been no exception to the general rule. The whole tendency of our civilization is, however, in the direction of humane methods in dealing with criminals and that form of execution which is quickest and least repulsive should be adopted. It is a mathematical impossibility that any human being receiving in proper form a electrical current of lethal energy should appreciate even for a fraction of a second the slightest pain. It has been ascertained that the brain is onetwenty-fifth of a second in recognizing an impression, and one-twenty-eighth of a second in telegraphing that an impression has been received, and as nerve force travels only about 100 feet a second, while the velocity of the electric current is millions of times greater than this, the brain has absolutely no time to appreciate a sense of pain. As between electricity and certain other methods of capital punishment, it is not altogether clear that the former is the best that

12 Jour. of Yerv and Mental Disease, 1880

13 Review of Insanity and Nervous Diseases, Vol. II. could be suggested. The guillotine and the garote are practically instantaneous and painless in their action and attended with only a fraction of the paraphernalia and expense of the method now adopted in New York State. There is, however, an apparent brutality attending both these methods that repels, and a mutilation and shedding of blood, which public opinion in this country seems unwilling to tolerate.

The action of poison is open to none of these objections, and it seems somewhat singular that it has not more strongly commended itself to the philanthropic mind seeking simpler and more humane methods in the legal taking of human life. But as between electricity and the rope there can, it seems to me, be no question. Let us suppose that it had been customary to execute by electricity instead of by hanging, and that some one in the supposed interests of humanity should suggest that the former method be abolished, and the latter substituted; that a method practically instantaneous and painless, unattended by mutilation and without any distressing outward manifestations of pain, be replaced by one which usually fails to extinguish life for ten or twelve minutes, which in many cases it is reasonable to believe is attended with torture, and where the convulsive manifestations are horrible to witness-such a suggestion could not have the slightest claim for serious consideration, and as a matter of fact would never be offered.

After the passage by the legislature of the State of New York, of the law substituting electricity for hanging in the execution of criminals, there arose a terrible storm of opposition that apparently had for its basis extensive commercial interests. It was claimed by the opponents of the new method, that electricity was by no means certain to destroy life without the infliction of great pain, and the popular mind was agitated by repeated assertions of the possibility and probability of repulsive disfigurement by the heat and chemical action that would necessarily be developed in the use of currents of such great power. To determine these points and to advise the State as to the best methods of procedure, a commission was appointed consisting of Dr. Charles Mac Donald, Chairman of the State Commission in Lunacy, Prof. L.H. Laudy of Columbia College, and the writer, who both at the Edison Laboratory and at the various prisons of the State, experimented largely upon animals, and tested many devices and methods for the application of the current. There could be no charge of cruelty in these investigations for in no single instance was there any evidence that the slightest pain was inflicted.

The largest animals, such as horses and a bull, instantly succumbed to an electric pressure of one thousand volts, while dogs and calves were as readily destroyed by five and six hundred volts.

But one impact of the current was found necessary, for death was instantaneous in every case.

Immediate examination after the opening of the circuit invariably failed to elicit the slightest respiration. or heart beat, and careful and persistent efforts at artificial respiration conducted by Dr. Fell of Buffalo with the latest and most approved appliances were without avail.

In view of the fact thus satisfactorily demonstrated that one thousand or at the most fifteen hundred volts would instantly kill any animal large or small, we very naturally inferred that any human being 